\title{
The assessment of headaches on the acute medical unit: is it adequate and how could it be improved? 篦
}

\author{
Authors: Sophie Binks, ${ }^{A}$ Anna Nagy, ${ }^{B}$ Jeban Ganesalingam ${ }^{C}$ and Abarna Ratnarajah ${ }^{D}$
}

\begin{abstract}
Neurological emergencies represent $15-25 \%$ of the medical take, second only to cardiac and respiratory cases. However, the UK's number of neurologists is lower than that of other developed nations. This quality improvement project aimed to develop a guideline to optimise acute headache management by non-specialists, informed by the findings of a survey and audit of doctors' knowledge and practice. In total, 62 doctors responded to our survey. 53/56 (94.6\%) agreed a guideline would be useful. Knowledge of some important causes of headache was high, but was lower for others, including cerebral venous sinus thrombosis and cervical artery dissection. A consultant neurologist deemed $14 / 27$ (51.9\%) of acute headache presentations audited pre-guidelines to have had appropriate management. After guideline launch, a re-audit demonstrated this proportion was $18 / 22(81.8 \%)(p=0.04)$. We conclude the investigation and management of acute headache requires optimisation and a guideline may help to achieve this.
\end{abstract}

KEYWORDS: Acute medicine, guideline, headache, lumbar puncture, thunderclap

\section{Introduction}

Neurological emergencies are the third leading trigger of acute medical presentations on call, representing $15-25 \%$ of the medical take. This is second only to cardiac and respiratory cases. ${ }^{1}$ Headaches account for a significant proportion within neurological emergencies. ${ }^{2,3}$

The UK's ratio of neurologists of 1:90,000 is less than that of other European countries. ${ }^{4}$ Combined with a high frequency of neurological presentations on the acute take, this means many patients do not receive a neurology opinion. In one study, $66 \%$ of acute take patients with a central nervous system presentation did not receive neurology review. Considering headache or seizure patients among this $66 \%$, it was deemed $40 \%$ would have benefited from neurology input. ${ }^{2}$ A rapid

Authors: ${ }^{A}$ academic neurology FY2, Brighton and Sussex University Hospitals NHS Trust, Brighton, UK; ${ }^{\mathrm{B}}$ academic stroke FY2, Brighton and Sussex University Hospitals NHS Trust, Brighton, UK; ${ }^{C}$ consultant in neurology, Brighton and Sussex University Hospitals NHS Trust, Brighton, UK; ${ }^{\mathrm{D}}$ consultant in acute medicine, Brighton and Sussex University Hospitals NHS Trust, Brighton, UK access neurology service and headache guideline were developed in response to this identified issue. ${ }^{2}$

The management of acute headache is complex; for example, in a patient presenting with thunderclap headache, the differential is not limited to subarachnoid haemorrhage (SAH). Many other serious aetiologies, including cervical artery dissection, posterior reversible encephalopathy syndrome (PRES), reversible cerebral vasoconstriction (RCVS), cerebral venous sinus thrombosis (CVST), pituitary apoplexy and temporal arteritis, are not excluded by computerised tomography (CT) head and lumbar puncture (LP) alone. ${ }^{5,6}$ Accessible guidelines can support doctors to make consistent, safe decisions and may ensure less familiar causes are at least considered. The management of common conditions such as migraines can also be challenging but is important for patient welfare and long-term disease trajectory. ${ }^{7}$

Brighton and Sussex University Hospitals NHS Trust (BSUH) provides general and tertiary neurosciences services to Brighton and parts of Sussex. ${ }^{8}$ This quality improvement project sought to develop an easy to follow, practical headache guideline for doctors of all grades. Before launch, we performed a survey of the trust's doctors to assess knowledge of acute headache management and the need for a guideline. An audit of headache management evaluated pre-survey clinical practice, including areas for improvement. This was followed by a re-audit to assess guideline impact after its introduction.

\section{Methods}

The survey

We developed a 10-item questionnaire with both free text and Likert scale questions to assess doctors' knowledge of causes and management of acute headache (Box 1). The survey was piloted in print with two doctors; following this pilot, a link to the survey (SurveyMonkey) was emailed to doctors of all grades, from foundation year 1 (FY1) to consultant. The survey was anonymous and remained open for 2 weeks from 24 April-5 May 2015 inclusive. Email and personal reminders were made to encourage a good response rate.

\section{The audit}

A list of all patients discharged from BSUH with a diagnosis of headache between 1 and 15 March 2015 inclusive was obtained from medical coding. Of the 34 cases identified, three paediatric patients and four re-admissions were excluded, 
Box 1. Survey questions prior to launch of headache guidelines

1. What grade are you?

FY1 / FY2 / CMT / GPVTS / speciality grade / registrar / consultant / other

2. In a typical week, how many patients do you see presenting with acute headache? $0 / 1-2$ / 3-4 / 5-6 / 7-8 / >9

3. Which of the following do you routinely examine in patients presenting with acute headache?

Neck stiffness / temporal arteries / fundi / thorough cranial nerve exam / upper \& lower limb power / upper \& lower limb sensation / reflexes / plantars / carotid bruits / mental status, eg AMT or similar / rash / lymphadenopathy Comments: (free text field)

4. What features in the history/examination would prompt you to organise neuro-imaging for a patient with an acute headache? Please list any you would routinely ask about/elicit.

5. On a scale of $\mathbf{0}-5$, how confident do you feel in RECOGNISING the following presentations of headache? $(0=$ not aware of condition, 1 = not at all confident, 2 = not confident, 3 = neutral, 4 = quite confident, 5 = very confident).

Subarachnoid haemorrhage / haemorrhagic stroke / pituitary apoplexy / posterior reversible encephalopathy syndrome (PRES) / cervical artery dissection / cerebral venous sinus thrombosis / reversible cerebral vasoconstriction (RCVS) / encephalitis / meningitis / acute exacerbation migraine / acute exacerbation cluster headache / carbon monoxide poisoning / acute glaucoma / temporal arteritis

6. On a scale of $0-5$, how confident do you feel in the initial MANAGEMENT of the following causes of headache? $(0=$ no knowledge, 1 = not at all confident $2=$ not confident $3=$ neutral 4 = quite confident 5 = very confident). Options the same as for question 5.

7. Please indicate your experience in managing these causes of headache. (Never seen a case / seen at least one case or suspected case / seen several cases or suspected cases / managed several cases of this condition).

Options the same as for question 5.

8. Would you find a trust acute headache guideline useful?

Yes / No / Useful for junior colleagues

Comments: (free text field)

9. If you are a senior grade (registrar/consultant), please indicate how you think junior knowledge/clerking of headache compares to the following presentations (not as good / about the same / better / much better).

Acute coronary syndromes / acute LVF / acute exacerbation of asthma / acute exacerbation of COPD / pneumonia / sepsis / pulmonary embolism / GI bleed / diabetic ketoacidosis / acute kidney injury / seizure

10. Case vignette: a 30-year-old lady presents with severe headache which reached maximum intensity within seconds. She is usually fit and well with normal BMI, has no relevant family history and her only medication is the oral contraceptive pill. Blood tests (FBC, U\&E, LFTs, CRP, ESR, INR) and CT brain is normal and her LP results are as follows:

- Opening pressure $27 \mathrm{~cm} \mathrm{H}$

- WCC 3, no organisms seen

- Protein $530 \mathrm{mg} / \mathrm{L}$

- CSF glucose $4 \mathrm{mmol}$ (paired plasma $6.1 \mathrm{mmol}$ )

- No xanthochromia. No evidence to support SAH

What is the next appropriate stage in management?

Discharge as SAH has been excluded / Keep under investigation for an alternative cause of headache / Discharge with OPD referral to neurology

$\mathrm{AMT}=$ abbreviated mental test; $\mathrm{BMI}=$ body mass index; $\mathrm{CMT}=$ core medical trainee; $\mathrm{COPD}=$ chronic obstructive pulmonary disease; $\mathrm{CRP}=\mathrm{C}$-reactive protein; $\mathrm{CSF}=$ cerebrospinal fluid; $\mathrm{CT}$ = computerised tomography; $\mathrm{ESR}=$ erythrocyte sedimentation rate; $\mathrm{FBC}=$ full blood count; $\mathrm{FY} 1$ = foundation year $1 ; \mathrm{FY} 2=$ foundation year $2 ; \mathrm{GI}=$ gastrointestinal; $\mathrm{GPVTS}=$ General Practice Vocational Training Scheme; INR = international normalised ratio; LFT = liver function test; $\mathrm{LP}=$ lumbar puncture; $\mathrm{LVF}=$ left ventricular function; $S A H=$ subarachnoid haemorrhage; $\mathrm{U} \& \mathrm{E}=$ urea and electrolytes; $\mathrm{WCC}=$ white cell count

leaving 27 eligible admissions. Information on presentation, investigations performed and initial and outcome diagnoses was collected from their discharge summaries by an academic FY2 doctor (SB) and reviewed by a consultant neurologist (JG) to assess the appropriateness of case management.

\section{The guideline}

The guideline was co-authored by an academic neurology FY2 doctor (SB) and an acute medical consultant (AR) using appropriate references (Fig 1)..$^{5,6,9-18}$ One previously published local guideline ${ }^{12}$ was consulted although such documents are not easily accessible, being frequently only available via hospital intranet sites. The BSUH guideline covers causes of acute primary and secondary headache presenting to the acute medical unit, except idiopathic intracranial hypertension, which has its own guideline. The draft guideline was reviewed by consultants from acute medicine, neurology and stroke before launch and presented to the trust Grand Rounds in July 2015. It was approved by the hospital drugs and therapeutics committee in November 2015 and incorporated into the trust's handbook of protocols on acute conditions for junior doctors. This is available via both the local intranet and on the MicroGuide ${ }^{\mathrm{TM}}$ platform, which may be downloaded to a mobile phone, further increasing accessibility. Awareness of the guideline was promoted through email and word of mouth. 


\section{Sophie Binks, Anna Nagy, Jeban Ganesalingam et al}

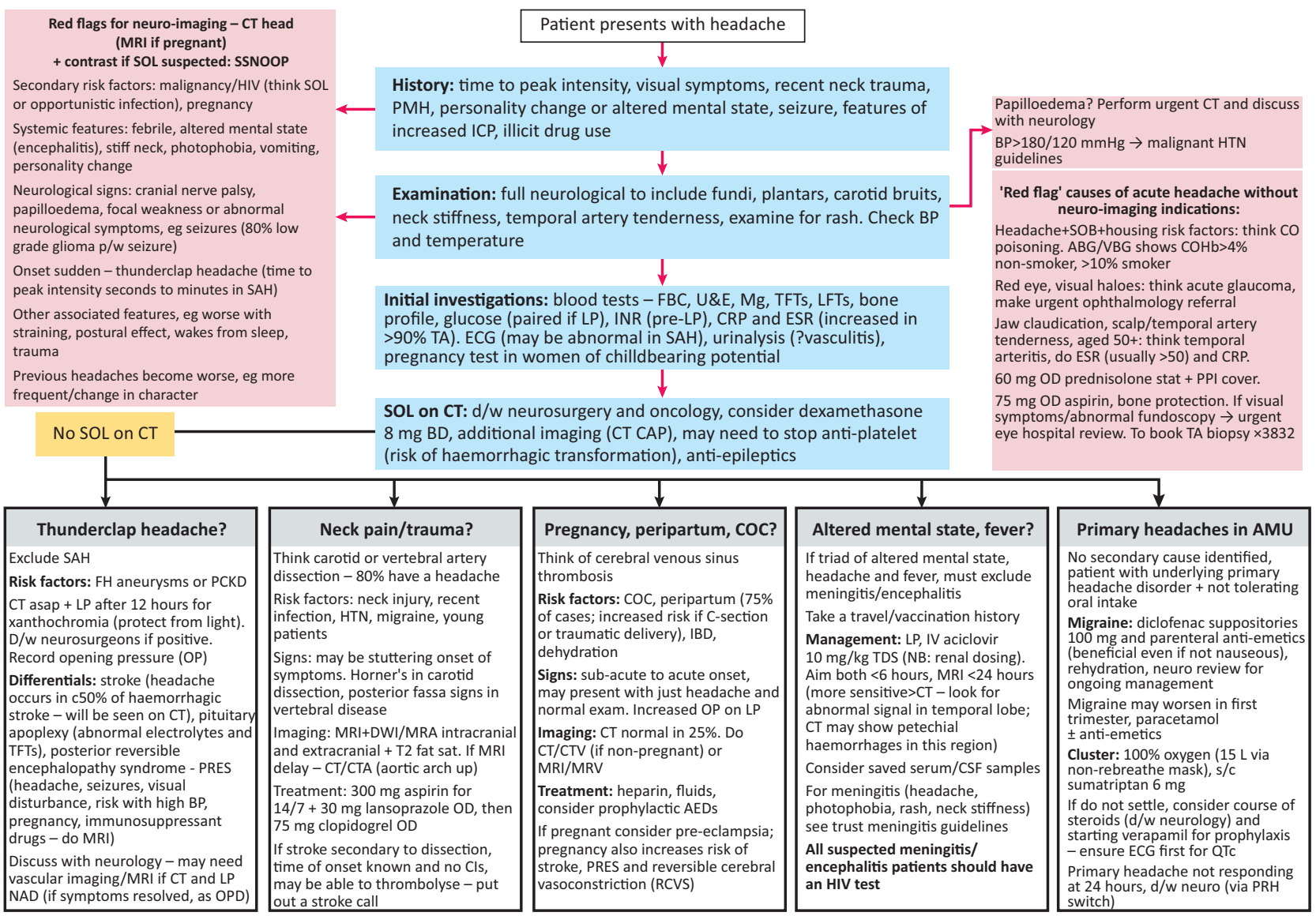

Fig 1. Brighton and Sussex University Hospitals NHS Trust acute headache guideline. $A B G=$ arterial blood gas; $A E D=$ enti-epileptic drug; $A M U=a c u t e$ medical unit; $\mathrm{BP}=$ blood pressure; $\mathrm{C}$-section = caesarean section; $\mathrm{CAP}=$ chest abdomen pelvis; $\mathrm{CI}=$ contraindication; $\mathrm{CO}=$ carbon monoxide; $\mathrm{COC}=\mathrm{combined}$ oral contraceptive pill; $\mathrm{CRP}=\mathrm{C}$-reactive protein; $\mathrm{CSF}=$ cerebrospinal fluid; $\mathrm{CT}$ = computerised tomography; $\mathrm{CTA}=$ computerised tomography angiography; $\mathrm{CTV}=$ computerised tomography venogram; $\mathrm{d} / \mathrm{w}$ = discuss with; $\mathrm{DWI}$ = diffusion-weighted imaging; $\mathrm{ECG}=$ electrocardiogram; $\mathrm{ESR}=$ erythrocyte sedimentation rate; $\mathrm{FBC}$ = full blood count; $\mathrm{FH}$ = family history; $\mathrm{HTN}$ = hypertension; $\mathrm{IBD}=$ inflammatory bowel disease; $\mathrm{ICP}=$ intracranial pressure; INR = international normalised ratio; $I V=$ intravenous; $L F T$ = liver function test; $L P=$ lumbar puncture; $\mathrm{Mg}=$ magnesium; $M R I=$ magnetic resonance imaging; $M R A=$ magnetic resonance angiography; $\mathrm{MRV}=$ magnetic resonance venogram; $\mathrm{NAD}=$ nothing abnormal detected; $\mathrm{OD}=$ once daily; $\mathrm{OP}=$ opening pressure; $\mathrm{OPD}=$ outpatient department; $\mathrm{PCKD}=$ polycystic kidney disease; $\mathrm{PMH}=$ past medical history; $\mathrm{PPI}=$ proton pump inhibitor; $\mathrm{PRH}=$ Princess Royal Hospital; $\mathrm{s} / \mathrm{c}=$ subcutaneous; $\mathrm{SAH}=$ subarachnoid haemorrhage; $\mathrm{SOB}=$ shortness of breath; $\mathrm{SOL}=$ space-occupying lesion; $\mathrm{TA}=$ temporal arteritis; $\mathrm{TDS}=$ three times a day; TFT = thyroid function test; $\mathrm{U} \& \mathrm{E}=$ urea and electrolytes; $\mathrm{VBG}=$ venous blood gas

\section{The re-audit}

Case finding was carried out using similar methodology to the original audit by an academic neurology FY2 doctor (AN) covering the period 4-17 July 2016, inclusive. 31 cases of headache were identified; three paediatric patients and three admitted under specialties without being seen by acute medicine were excluded, while further information on two of the cases was not available. On further review, one case had self-discharged and was excluded from analysis of case management, leaving 22 cases.

\section{Results of the survey}

Questions 1 and 2: respondent profile and frequency of seeing headache patients

62 doctors participated in the survey, of whom 56 completed all questions. Respondents consisted of six consultants (10\%), 16 registrars $(26 \%), 11$ core medical trainees (18\%), 11 FY2 doctors (18\%), $16 \mathrm{FY} 1$ doctors (26\%) and two doctors from specialty or research grades $(2 \%)$.

Headache was identified as a frequent clinical presentation. Of all 62 respondents, 32 (51.6\%) stated they saw, on average, 1-2 patients with headache per week, 14 (22.6\%) replied they saw 3-4 per week, three (4.8\%) saw 5-6 cases per week and two $(3.2 \%)$ estimated they saw more than nine individuals with headache per week.

\section{Question 3: clinical examination}

Doctors were asked which elements of a neurological exam they would perform on a patient presenting with acute headache. Almost all of the 62 doctors indicated they would interrogate neck stiffness (98.4\%) and upper and lower limb power (93.5\%). Most would look for rash $(87.1 \%)$, complete a thorough cranial nerve assessment $(83.9 \%)$, examine sensation $(79 \%)$ and test plantars and reflexes (77.4\%). Only $40.3 \%$ agreed they would do 
fundoscopy, with free text comments suggesting that difficulty in accessing equipment was a key factor.

\section{Questions 5 and 6: recognition and management of causes of acute headache}

For these questions, participants ranked their confidence in their recognition and initial management of a variety of causes of headache on a scale of $0-5$, where 0 was equivalent to no knowledge and 5 to high levels of knowledge. Mean scores of 4-5 represent good confidence levels whereas scores of $<3$ indicate a lack of confidence.

Confidence was high in some conditions, for example mean scores of 4 and above were obtained for recognition of meningitis, $\mathrm{SAH}$, acute migraine and encephalitis and for initial management of meningitis, temporal arteritis, encephalitis and SAH. However, confidence for other conditions was lower including CVST, cervical artery dissection, carbon monoxide poisoning and acute glaucoma. It is worth noting that incidence rates of cervical artery dissection $(2.6-3 / 100,000)^{16}$ and CVST $(1.3 / 100,000),{ }^{6}$ two conditions where confidence was low, exceed that of herpes simplex encephalitis $(1 / 250,000-500,000) .{ }^{19}$

Confidence levels were not only decreased among juniors but other grades too. Taking the three pathophysiologies that ranked lowest for confidence in recognition and management, $33 \%(5 / 15)$ of registrars selected a score of $0-2$ for recognition of pituitary apoplexy and 60\% (9/15) for both RCVS and PRES. When considering initial management, $40 \%(6 / 15)$ of registrars selected a score of $0-2$ for pituitary apoplexy, while 8/15 (53.3\%) chose one of these scores for PRES or RCVS. Some consultants were also not confident in the recognition or management of either PRES or RCVS.

\section{Question 7: experience in managing different causes of headache}

When questioned on their experience of managing different causes of acute headache, participant responses reflected the answers given to the previous two questions. The three conditions in which doctors had the least experience were RCVS (80.4\% never having seen a case), PRES (76.8\% never having seen a case) and pituitary apoplexy (62.5\% never having seen a case). More than half had never seen a case of cervical artery dissection, acute glaucoma and carbon monoxide poisoning. Again, this was not confined merely to junior grades: of 15 registrars, $11(73.3 \%)$ had never (to their knowledge) seen a case of RCVS, 10 (66.7\%) of PRES, six (40\%) of acute glaucoma and four (26.7\%) of pituitary apoplexy, cervical artery dissection or carbon monoxide poisoning (Fig 2A).

\section{Question 8: need for a headache guideline}

$53 / 56(94.6 \%)$ of respondents indicated they would find a headache guideline useful.

\section{Questions 9 and 10: estimation of juniors' knowledge of headache management compared with other acute presentations and answers to a clinical scenario}

Consultants and registrars were asked to rate junior doctors' knowledge of headache compared with other acute pathologies (Fig 2B). Eleven (50\%) or more of the 22 doctors who answered this question thought headache knowledge was 'not as good' as the other causes listed, with the exception of acute kidney injury, where $10(45.5 \%)$ thought knowledge was not as good as for headache, and seizure, where this percentage was $22.7 \%$ (five respondents). Overall, junior doctor knowledge of headache was not rated as 'much better' or 'better' than any other of the presentations listed.

The 'correct' answer to the clinical scenario of question 10 (Box 1) was to keep the patient in for further investigation, as CVST would need to be excluded in a female patient on the oral contraceptive pill with a raised opening pressure and protein on LP. More than three-quarters $(77 \%, 43 / 56)$ chose this option, but nevertheless 12 individuals would have elected to discharge this patient with outpatient neurology follow-up.

\section{Results of the audit}

The age of patients presenting with headache within the audit period ranged from 18-91 years. Of these, 19 (70\%) were female and eight (30\%) male. Overall, 12 patients (44.4\%) underwent LP, $23(85.2 \%)$ had a CT head, eight $(29.6 \%)$ had magnetic resonance imaging (MRI) and six (22.2\%) some form of angiography, either CT or MRI. On review by a consultant neurologist, 51.9\% (14/27) were deemed to have been appropriately investigated and managed. Examples of inappropriate management included unnecessary investigations and, in other cases, the appropriate imaging modality not being selected.

\section{Results of the re-audit}

Patient age in the re-audit ranged from $17-83$ years. Of these, $13(56.5 \%)$ were female and $10(43.5 \%)$ male. The management of 22 patients was analysed. Six patients (27.2\%) underwent LP, 17 (77.3\%) had a CT head and two (9\%) had MRI or angiography. On review by a consultant neurologist, $81.8 \%$ (18/22) were deemed appropriately investigated. Compared with the prelaunch audit, this difference was significant (Fisher's exact test, $\mathrm{p}=0.04$ ). The decrease in imaging studies was non-significant.

A list of outcome diagnoses for the audit and re-audit can be found in Table 1. The leading discharge diagnoses were migraine $(10 / 49,20 \%)$, followed by primary headache, unspecified $(8 / 49,16 \%)$ and viral illness $(5 / 49,10 \%)$.

\section{Discussion}

This study has revealed several positive findings. Most doctors felt confident managing certain life-threatening conditions such as meningitis, encephalitis, SAH and haemorrhagic stroke. Most would also carry out a thorough assessment of a headache patient. However, it has also has highlighted several serious conditions where the management could be improved.

Firstly, a minority of doctors would perform fundoscopy $(40.3 \%)$. Free text answers suggested difficulty in accessing equipment played a role, but it is also possible that technical ability is another factor. ${ }^{20}$ Secondly, confidence in managing conditions such as cervical artery dissection, CVST, RCVS, PRES, glaucoma and carbon monoxide poisoning was poor. This was demonstrated in the questionnaire (question 10) where nearly a quarter of doctors might miss a CVST.

In addition to survey evidence of potentially unrecognised CVST, the pre-launch audit identified patient management could be improved in around $50 \%$ of cases. No cause for headache was stated in a significant minority $(8 / 49,16 \%)$ of 


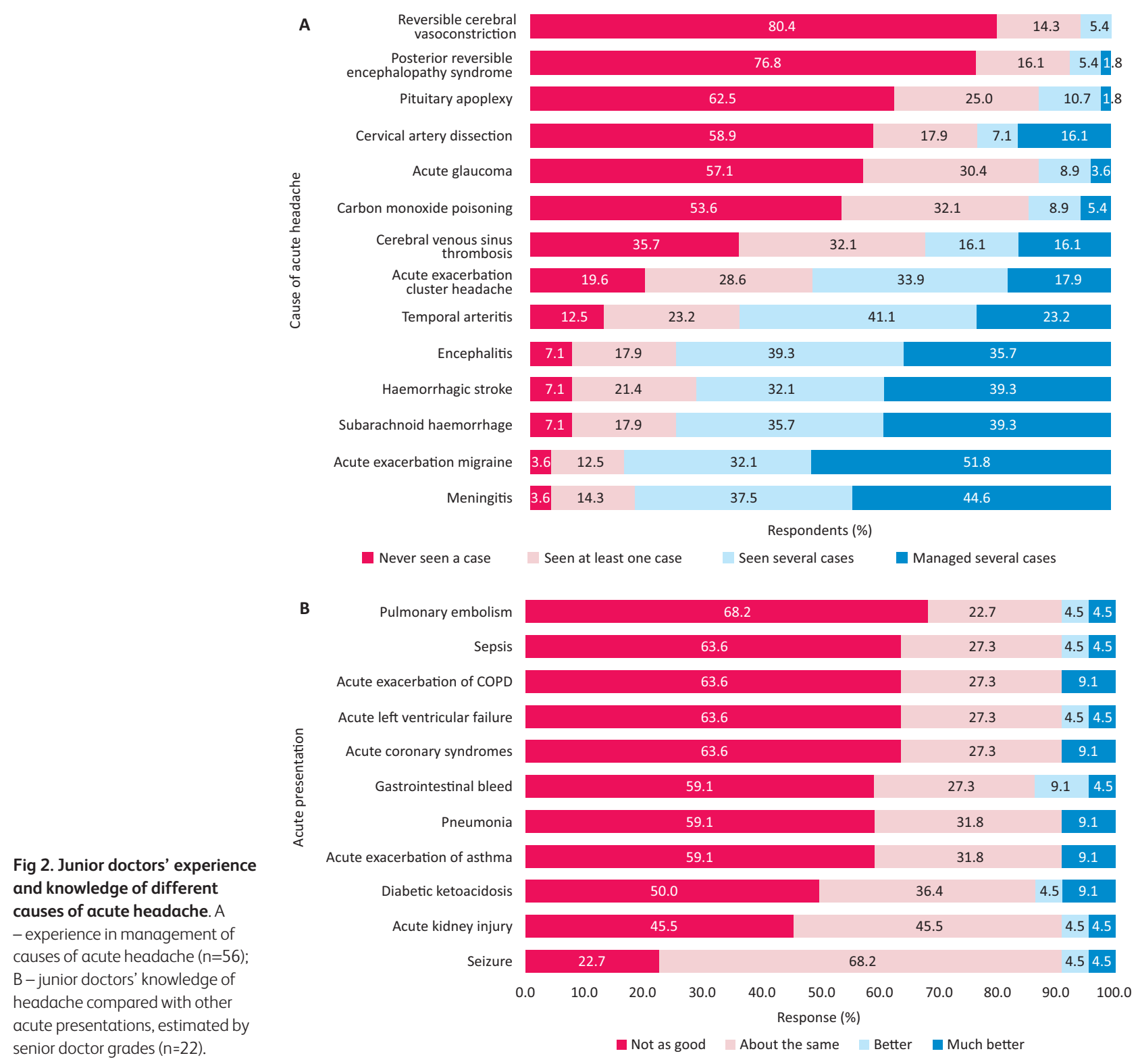

audit and re-audit patients, which may reflect difficulty in reaching a diagnosis. Neurology input may have been beneficial in these cases. It was not possible to assess from the records we consulted why neurology input remained low, at around 22\% in both case series, especially as BSUH provides a same or nextday neurology consult service on weekdays, with telephone coverage at the weekend. This is in line with the Association of British Neurologists recommendation that daily neurological review is made available even if this is by telemedicine. ${ }^{21}$

Appropriate headache management increased significantly ( $\mathrm{p}=0.04)$ from $51.9 \%(14 / 27)$ before the launch of the guideline, to $81.8 \%(18 / 22)$ in the post-guideline audit. Since the number of cases that had specialist neurology input in both audits was almost identical $(22.2 \%(6 / 27)$ in the audit and $22.7 \%(5 / 22)$ in the re-audit), it is possible the guideline directly influenced this improvement. However, our sample size is small and the re-audit was preceded by a period of concerted awareness raising. Further re-audit would be required to ascertain whether sustained improvement in headache management can be achieved.

The guideline aim is to improve patient care through timely and well-targeted investigations. Enhancing acute neurological services through availability of specialist review would be expensive and potentially challenging, with the available numbers of neurologists still not reaching the Royal College of Physicians' recommendation of 1:69,500 of population. ${ }^{22}$ Countries, like Canada, that provide a daily acute neurology consult model to see all neurological admissions have a greater ratio of neurologists to populace, reported at 1:33,000 head of population in Canada for $2014 .{ }^{23}$ Moreover, the Shape of Training review, if implemented, could affect numbers of higher specialty trainees in neurology. ${ }^{24}$

Junior doctors' headache knowledge was deemed poorer than almost any other acute medical presentation listed, and only for seizure - another neurological emergency - was it 
Table 1. Outcome diagnoses of 49 cases of acute headache

\begin{tabular}{|c|c|c|c|}
\hline Diagnosis & $\begin{array}{l}\text { Number } \\
\text { of audit } \\
\text { patients }\end{array}$ & $\begin{array}{l}\text { Number } \\
\text { of re-audit } \\
\text { patients }\end{array}$ & $\begin{array}{l}\text { Proportion of } \\
\text { all patients } \\
(\%)\end{array}$ \\
\hline \multicolumn{4}{|l|}{$\begin{array}{l}\text { Primary headache } \\
\text { disorders }\end{array}$} \\
\hline Headache unspecified & 4 & 4 & $16 \%$ \\
\hline Migraine & 6 & 4 & $20 \%$ \\
\hline Tension headache & 2 & 2 & $8 \%$ \\
\hline \multicolumn{4}{|l|}{$\begin{array}{l}\text { Secondary causes of } \\
\text { headache }\end{array}$} \\
\hline Bacterial meningitis & 1 & 0 & $2 \%$ \\
\hline Brain metastases & 0 & 1 & $2 \%$ \\
\hline $\begin{array}{l}\text { Cervicogenic or } \\
\text { musculoskeletal } \\
\text { headache }\end{array}$ & 1 & 1 & $4 \%$ \\
\hline Confirmed SAH & 1 & 0 & $2 \%$ \\
\hline Drug related & 2 & 0 & $4 \%$ \\
\hline Hyperglycaemia & 0 & 1 & $2 \%$ \\
\hline Hypertensive & 2 & 0 & $4 \%$ \\
\hline Inner ear pathology & 0 & 1 & $2 \%$ \\
\hline Possible IIH & 0 & 1 & $2 \%$ \\
\hline $\begin{array}{l}\text { Post-viral headache with } \\
\text { postural hypotension }\end{array}$ & 0 & 1 & $2 \%$ \\
\hline $\begin{array}{l}\text { Post-lumbar puncture } \\
\text { headache }\end{array}$ & 0 & 1 & $2 \%$ \\
\hline SAH excluded* & 2 & 0 & $4 \%$ \\
\hline Sarcoid & 0 & 1 & $2 \%$ \\
\hline Temporal arteritis & 4 & 0 & $8 \%$ \\
\hline $\begin{array}{l}\text { Transient ischaemic } \\
\text { attack }\end{array}$ & 2 & 0 & $4 \%$ \\
\hline Viral illness & 2 & 3 & $10 \%$ \\
\hline Viral meningitis & 0 & 2 & $4 \%$ \\
\hline Total & 29 & 23 & - \\
\hline
\end{tabular}

${ }^{*}$ One patient discharged and SAH excluded on subsequent re-admission. One patient xanthochromia positive, but all imaging negative.

Two audit and one re-audit patient had dual pathology headache. IIH = idiopathic intracranial hypertension; SAH = subarachnoid haemorrhage

judged similar. Confidence gaps existed even at senior level. Our results support the case not only for use of a guideline in acute headache management, but also for increased medical education on this topic, including medical school, junior doctor and other postgraduate teaching.

\section{Strengths and weaknesses of this study}

This project was carried out within a single trust and thus reflects local strengths and weaknesses. For example, Brighton has one of the highest prevalences of HIV in the UK, ${ }^{25}$ which may account for the good levels of confidence in dealing with infectious causes of headache. The small number of consultant responses (six) means the survey is subject to responder bias and these figures should not be over-interpreted. Since total number of replies when broken down by each grade was also relatively small, care should be taken when interpreting survey findings for subgroups of responders. Unfortunately, no GP trainees responded to the questionnaire, which is disappointing as headache is an important neurological presentation in primary care. ${ }^{26}$ The sample sizes of the audit and re-audit were both small, gathered a limited set of data and consultant review was not blinded to pre- or post-guideline status.

Strengths include the assessment of an important clinical topic through different methods, which can help counterbalance weaknesses in either one technique. A variety of doctors answered our questionnaire and highlighted some important deficits in headache management. We achieved nearunanimous support for a guideline and measured a positive impact through re-audit.

\section{Summary and implications}

Patients with neurological problems, including those with headache, are common on the acute take, but access to neurological expertise is hampered by the relatively low provision of neurologists in the UK. ${ }^{4}$ Our survey of doctors showed room for improvement in knowledge and confidence in some acute headache presentations. A guideline, created with input from relevant specialties, is one method to address this. Other strategies include undergraduate and postgraduate teaching, focusing on topics where confidence was shown to be low and, in the longer term, appropriate specialist workforce planning.

\section{Author contributions}

$\mathrm{SB}$, JG and AR made substantial contributions to the conception and design of the study and SB, AN, JG and AR were involved in the acquisition, analysis and interpretation of data. SB, AN, JG and AR drafted the article and approved the final version for publication.

\section{Conflicts of interest}

SB and AN hold NIHR-funded clinical fellowships.

\section{Acknowledgements}

The authors would like to acknowledge Dr Sue Lipscombe for her review and helpful comments on the draft manuscript.

\section{References}

1 Royal College of Physicians. Local adult neurology services for the next decade. Report of a working party. London: RCP, 2011.

2 Chapman FA, Pope AE, Sorensen D et al. Acute neurological problems: frequency, consultation patterns and the uses of a rapid access neurology clinic. J R Coll Physicians Edinb 2009;39:296-300.

3 Weatherall MW. Acute neurology in a twenty-first century district general hospital. J R Coll Physicians Edinb 2006;36:196-200.

4 Morrish PK. Inadequate neurology services undermine patient care in the UK. BMJ 2015;350:h3284.

5 Ducros A, Bousser MG. Thunderclap headache. BMJ 2013;346:e8557.

6 Dilli E. Thunderclap headache. Curr Neurol Neurosci Rep 2014;14:437. 
7 Lipton R, Fanning KM, Serrano D et al. Ineffective treatment of episodic migraine is associated with new-onset chronic migraine. Neurology 2015;84:689-95.

8 Brighton and Sussex University Hospitals NHS Trust. Annual Report 2013-2014. Brighton: BSUH, 2014. www.bsuh.nhs.uk/wp-content/ uploads/sites/5/2016/08/Annual-Report-web-version.pdf [Accessed 13 January 2017].

9 National Institute for Health and Care Excellence. Headaches in over 12s: diagnosis and management. NICE clinical guideline No 150. London: NICE, 2012.

10 Scottish Intercollegiate Guidelines Network. Diagnosis and management of headache in adults. A national clinical guideline. SIGN clinical guideline No 107. Edinburgh: SIGN, 2008.

11 British Association for the Study of Headache. Guidelines for all healthcare professionals in the diagnosis and management of migraine, tension-type headache, cluster headache, medicationoveruse headache, 3rd edn. Hull: BASH, 2010.

12 Nottinghamshire Area Prescribing Committee. Adult headache guideline. Nottingham: Nottinghamshire Area Prescribing Committee, 2016. http://www.nottsapc.nhs.uk/media/1040/adult-headachepathway.pdf [Accessed 13 January 2017].

13 CADISS trial investigators. Antiplatelet treatment compared with anticoagulation treatment for cervical artery dissection (CADISS): a randomised trial. Lancet Neurol 2015;14:361-7.

14 Edlow JA, Caplan LR, O'Brien K et al. Diagnosis of acute neurological emergencies in pregnant and post-partum women. Lancet Neurol 2013;12:175-85.

15 Friedman BW, Grosberg BM. Diagnosis and management of the primary headache disorders in the emergency department setting. Emerg Med Clin North Am 2009;27:71-87.

16 Vestergaard K, Andersen G, Nielsen MI et al. Headache in stroke. Stroke 1993;24:1621-4.
17 Debette S. Pathophysiology and risk factors of cervical artery dissection: what have we learnt from large hospital-based cohorts? Curr Opin Neurol 2014;27:20-8.

18 Dasgupta B, Group Giant Cell Arteritis Guideline Development. Concise guidance: diagnosis and management of giant cell arteritis. Clin Med 2010;10:381-6.

19 Solomon T, Michael BD, Smith PE et al. Management of suspected viral encephalitis in adults - Association of British Neurologists and British Infection Association Guidelines. J Infect 2012;64:347-73.

20 Mackay DD, Garza PS, Bruce BB et al. The demise of direct ophthalmoscopy: a modern clinical challenge. Neurol Clin Pract 2015;5:150-7.

21 Association of British Neurologists. ABN acute neurology services survey 2014. London: ABN, 2014.

22 Llewelyn G. Neurology. In: Royal College of Physicians. Consultant physicians working with patients, 5th edn. London: RCP, 2013:173-80.

23 Canadian Institute for Health Information. Physicians in Canada, 2014. Ottawa: CIHI, 2015.

24 Greenaway D. Securing the future of excellent patient care. London: Shape of Training, 2013.

25 Public Health England. HIV in the United Kingdom: 2014 report. London: PHE, 2014.

26 Latinovic R, Guilliford M, Ridsdale L. Headache and migraine in primary care: consultation, prescription, and referral rates in a large population. J Neurol Neurosurg Psychiatry 2006;77:385-7.

Address for correspondence: Dr Sophie Binks, Nuffield Department of Clinical Neurosciences, West Wing, Level 6, John Radcliffe Hospital, Oxford OX3 9DU, UK. Email: sophiebinks@doctors.org.uk

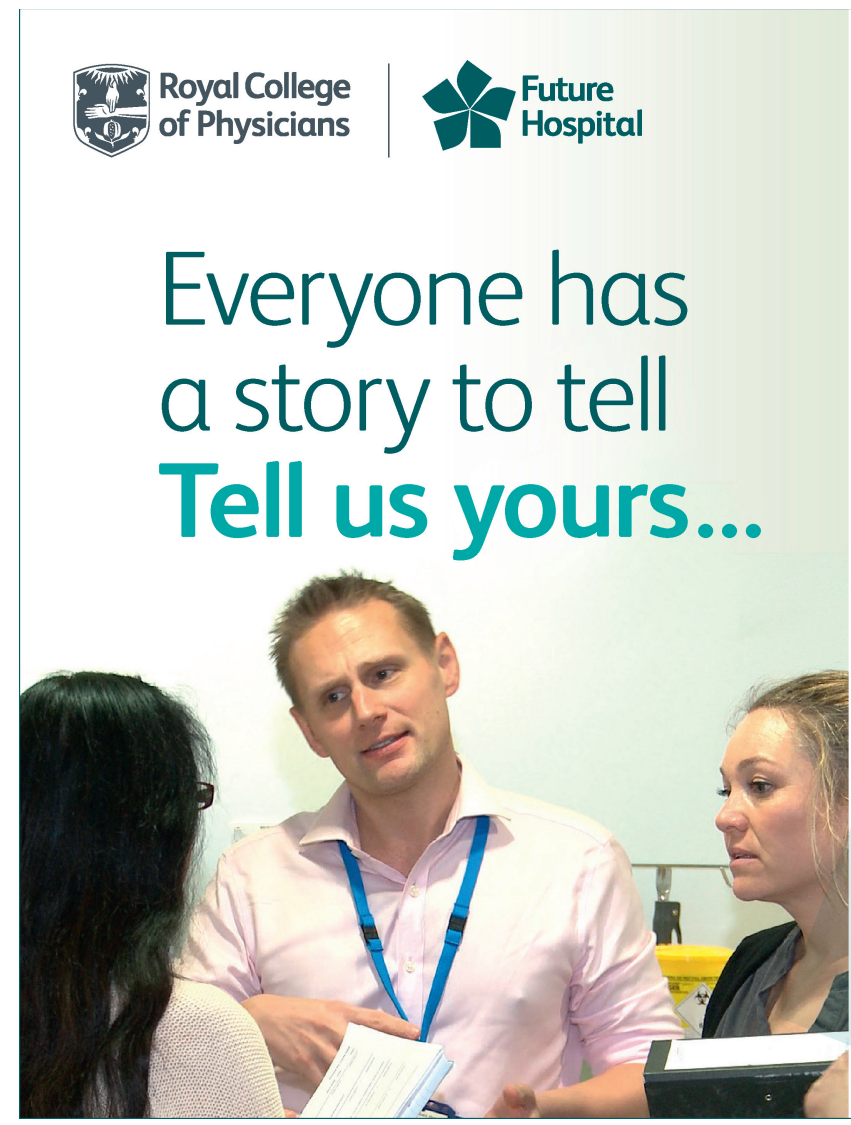

The Future Hospital Programme (FHP) aims to develop and implement the RCP's vision for the future of medical care in hospital and community settings. We are keen to showcase examples of best and innovative practice to improve patient care, and would very much like to hear more about your work.

We are asking people to share their stories to create, grow and connect a future hospital network. These stories of best and innovative practice and patient care may be featured on the RCP website as exemplars of FHP principles and recommendations in action.

To share your story

Visit: www.rcplondon.ac.uk/FH-tell-us-your-story

For further information

Visit: www.rcplondon.ac.uk/FHP

or contact

futurehospital@rcplondon.ac.uk 